\title{
Reduced face identity aftereffects in relatives of children with autism
}

\author{
Chiara Fiorentini ${ }^{\text {a,b,c,*, }}$, Laura Gray ${ }^{\mathrm{d}}$, Gillian Rhodes ${ }^{\mathrm{c}}$, Linda Jeffery ${ }^{\mathrm{c}}$, Elizabeth Pellicano ${ }^{\mathrm{c}, \mathrm{d}}$ \\ a Institute of Child Health, University College London, London \\ ${ }^{\mathrm{b}}$ Department of Psychology, The Australian National University, Australia \\ ${ }^{c}$ ARC Centre of Excellence in Cognition and its Disorders, School of Psychology, University of Western Australia, Australia \\ ${ }^{\mathrm{d}}$ Centre for Research in Autism and Education (CRAE), Institute of Education, University of London, London
}

\section{A R T I C L E I N F O}

\section{Article history:}

Received 23 February 2012

Received in revised form

23 August 2012

Accepted 24 August 2012

Available online 5 September 2012

\section{Keywords:}

Autism

Endophenotype

Faces

Aftereffects

Adaptation

\begin{abstract}
A B S T R A C T
Autism is a pervasive developmental condition with complex aetiology. To aid the discovery of genetic mechanisms, researchers have turned towards identifying potential endophenotypes - subtle neurobiological or neurocognitive traits present in individuals with autism and their "unaffected" relatives. Previous research has shown that relatives of individuals with autism exhibit face processing atypicalities, which are similar in nature albeit of lesser degree, to those found in children and adults with autism. Yet very few studies have examined the underlying mechanisms responsible for such atypicalities. Here, we investigated whether atypicalities in adaptive norm-based coding of faces are present in relatives of children with autism, similar to those previously reported in children with autism. To test this possibility, we administered a face identity aftereffect task in which adaptation to a particular face biases perception towards the opposite identity, so that a previously neutral face (i.e., the average face) takes on the computationally opposite identity. Parents and siblings of individuals with autism showed smaller aftereffects compared to parents and siblings of typically developing children, especially so when the adapting stimuli were located further away from the average face. In addition, both groups showed stronger aftereffects for adaptors far from the average than for adaptors closer to the average. These results suggest that, in relatives of children with autism, face-coding mechanism are similar (i.e., norm-based) but less efficient than in relatives of typical children. This finding points towards the possibility that diminished adaptive mechanisms might represent a neurocognitive endophenotype for autism.
\end{abstract}

(c) 2012 Elsevier Ltd. All rights reserved.

\section{Introduction}

Autism spectrum disorders (ASD) are pervasive developmental conditions characterised by often striking difficulties in social communication and social interaction in addition to repetitive and unusually focused behaviours and interests (American Psychiatric Association, 2000). Early twin and family history studies firmly established that genetic factors play a crucial role in the aetiology of autism (Bailey et al., 1995; Bolton et al., 1994; Folstein \& Rutter, 1977). Yet, despite numerous studies using linkage or candidate gene approaches, the discovery of a single genetic locus of major effect has not been forthcoming. Instead, there is now clear consensus among geneticists that autism is both oligogenic - resulting from the action of multiple interacting genes - and multifactorial - resulting from interactions between

\footnotetext{
* Corresponding author at: Department of Psychology, The Australian National University, Canberra ACT 0200, Australia. Tel.: +61 02612 5416; fax: +610261250499.

E-mail address: fiorentinichiara@gmail.com (C. Fiorentini).
}

genes and environmental factors, which have yet to be fully identified (see Geschwind, 2011, for review).

A significant minority of parents and siblings of individuals with ASD show behavioural traits that are qualitatively similar to the defining features of ASD, albeit in more subtle form (see Bailey, Palferman, Heavey, \& Le Couteur, 1998, for review). Many studies have attempted to identify the various components of this so-called "broad autism phenotype", which can include rigid or aloof personality traits, difficulties initiating and maintaining friendships, limited communicative use of language, and overly focused and unusual interests and activities (Bishop, Maybery, Wong, Maley, \& Hallmayer 2006; Losh, Childress, Lam, \& Piven, 2008; Losh \& Piven, 2007; Piven, Palmer, Jacobi, Childress, \& Arndt, 1997).

Focusing on the behavioural level alone, however, is not an ideal basis for identifying genetic mechanisms: the same genotype can give rise to different behavioural phenotypes, and the same phenotype can arise from a range of genotypes (Gottesman \& Gould, 2003). Researchers have therefore turned their attention towards discovering neurobiological or cognitive markers that are initially unobservable but which are more proximal to the underlying 
aetiology of autism than overt behaviours themselves. Such "endophenotypes" are thought to index genetic liability to autism in otherwise apparently "unaffected" individuals (Flint \& Munafò, 2007).

Atypical face-processing mechanisms have been proposed to be one such candidate endophenotype for autism (Dawson et al. 2002). Difficulties in perceiving and discriminating faces have been well documented in individuals with ASD (e.g., see Dawson, Webb, \& McPartland, 2005, for review). Children and adults with ASD show poorer performance on a variety of face processing tasks compared with non-autistic individuals, including face recognition (Boucher, Lewis, \& Collis, 1998; Ewing, Pellicano, \& Rhodes, 2011a), face discrimination (Ewing et al., 2011a; Wallace, Coleman, \& Bailey, 2008a), expression recognition (Rump, Giovannelli, Minshew, \& Strauss, 2009; Wallace, Coleman, \& Bailey, 2008b), and eye-gaze perception (Wallace, Coleman, Pascalis, \& Bailey, 2006). Even when their performance is similar to that of non-autistic individuals, individuals with ASD appear to use atypical strategies, such as paying more attention to the mouth than the eyes (Klin, Jones, Schultz, Volkmar, \& Cohen, 2002; Neumann, Spezio, Piven, \& Adolphs, 2006; although see Falck-Ytter \& von Hofsten, 2011, for a critique), and applying a local rather than holistic processing style (Joseph \& Tanaka, 2002).

A similar range of face processing atypicalities has also been reported in parents and siblings of individuals with ASD. Such atypicalities include less time spent looking at the eyes during a face processing task (Dalton, Nacewicz, Alexander \& Davidson, 2005), difficulties discriminating subtle differences between faces, identifying facial expressions of fear and disgust, and judging direct eye contact (Wallace, Sebastian, Pellicano, Parr, \& Bailey, 2010) and problems on a standardized test of facial identity recognition (Wilson, Freeman, Brock, Burton, \& Palermo, 2010), compared to parents and siblings of typically developing individuals. These studies clearly show that atypicalities in various behavioural aspects of face processing are shared by individuals with autism and their relatives.

Studies that go one step further to pinpoint the underlying mechanisms responsible for such atypicalities in relatives of individuals with autism should therefore bring us closer for isolating a potential endophenotype for autism at the neurocognitive level. One study has demonstrated distinct face-processing strategies during emotion recognition in relatives of individuals with ASD (Adolphs, Spezio, Parlier, \& Piven, 2008). These authors showed that parents of typical children showed substantial use of the eyes when judging emotions like fear or happiness. Yet parents of autistic children, especially those with an aloof personality, made much less use of the eyes when making these judgments, using more cues from the mouth (Adolphs et al., 2008), a strategy that closely mirrors the behaviour of individuals diagnosed with ASD (Spezio, Adolphs, Hurley, \& Piven, 2007).

The present study extends the search for candidate endophenotypes for autism by focusing on mechanisms underlying another important aspect of face processing the recognition of facial identity.

Typical children and adults code faces relative to an implicitlystored internal average or norm, which is continuously updated by experience to represent the central tendency of the population of faces experienced (for review see Rhodes \& Leopold, 2011). The strongest evidence for this adaptive norm-based coding mechanism comes from aftereffect paradigms. Aftereffects occur throughout perceptual systems and are illustrative of how perceptual attributes, such as colour and motion, are coded by these systems. For example, the motion aftereffect occurs when adaptation (prolonged exposure) to a stimulus moving in a particular direction causes a subsequently viewed stationary stimulus to be perceived as moving in the opposite direction. Similarly, in face identity aftereffects, adapting to a face biases us to see a subsequent face as having opposite properties (e.g., Leopold, O'Toole, Vetter, \& Blanz, 2001).

In a typical face identity aftereffect task, participants learn some target identities (e.g., Ted and Rob; see Fig. 1), and are then tested on their recognition of faces with weaker identity strengths of Ted (e.g., 30\%, $60 \%$, etc., including $0 \%$ average face) both before and after adaptation to anti-Ted. In typical adults (e.g., Leopold et al., 2001; Rhodes \& Jeffery, 2006) and children (e.g., Nishimura, Maurer, Jeffery, Pellicano, \& Rhodes, 2008), identification of the target identity (e.g., Ted) is facilitated following adaptation to its antiface (antiTed), that is, a face with opposite properties. For example, if Ted has smaller lips than average, antiTed will have larger lips than average, and so on for many other facial attributes. In terms of face space, anti-faces lie along the same vector as the target identity, but are situated on the other side of the average face. After adaptation to antiTed, the previously neutral $0 \%$ (average) face will be perceived as Ted. Adaptation to antiTed "shifts" the observer's internal average toward anti-Ted, causing the actual average (identity neutral) to look more like Ted. Furthermore, the identity aftereffect is selective for opposite face pairs (e.g., Ted/anti-Ted but not Ted/anti-Rob), suggesting that facial identity is coded opponently, with pairs of neural populations coding for above- and below-average values along particular dimensions in face space (Rhodes \& Jeffery, 2006; Rhodes et al., 2005; Robbins, McKone, \& Edwards, 2007).

Pellicano, Jeffery, Burr and Rhodes (2007) investigated adaptation to facial identity in children with and without ASD aged between 8 and 13 years. They found that the extent to which the children shifted their perception following adaptation was significantly attenuated in those with autism. Furthermore, the degree of adaptation correlated significantly and negatively with children's current levels of autistic symptoms, such that the children with the smallest aftereffects exhibited greater levels of symptoms. These findings suggest that the mechanisms responsible for coding facial identity might be less flexible or adaptable in children with autism, so that, relative to typical children, they

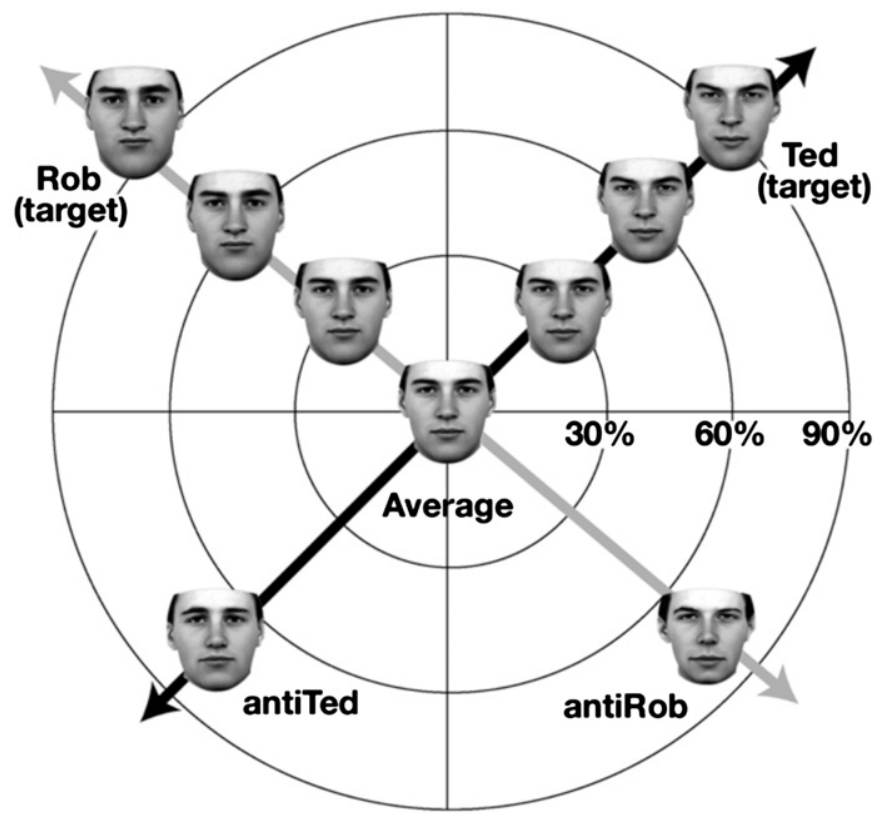

Fig. 1. A simplified face-space showing an average face, two target faces, Ted and Rob, and their opposite "antifaces". "Weaker" versions of each target were made by morphing each target with the average face by different amounts e.g., $60 \%$ Ted and $30 \%$ Ted as shown here. Adapting to antiTed facilitates recognition of Ted, so that "weaker" versions of Ted are more accurately identified and the average face takes on the appearance of Ted, but recognition of Rob is not facilitated. 
might be less capable of generating and updating face norms with experience (Pellicano et al., 2007).

The primary aim of the current study was to investigate whether diminished face adaptation might be a candidate endophenotype for autism. To address this aim, we administered a face identity aftereffect task to parents and siblings of children with and without autism. If atypicalities in adaptive face-coding mechanisms are a potential neurocognitive endophenotype for ASD, then we should expect attenuated face identity aftereffects in relatives of individuals with autism compared with relatives of typically developing children.

A secondary aim was to determine whether the face coding mechanisms shown by the parents and siblings of children with autism differ qualitatively from those seen in typical children and adults. In typical individuals, more physically extreme adaptors (e.g., faces that lie further away from the average) produce a larger change or bias in perception of the average face than less extreme adaptors (Jeffery et al., 2010; Jeffery et al., 2011; Robbins et al., 2007). This result is consistent with an opponent (normbased) coding model in which face dimensions (e.g., the size of the lips) are coded by the relative output of only two oppositely tuned pools of neurons: one pool responds maximally to one extreme of the value range (e.g., very small lips) and minimally to the opposite extreme (e.g., very large lips), while the other shows the reverse tuning. A larger aftereffect for more extreme adaptors is not consistent with a multi-channel, exemplar-based coding system, in which values along a dimension are coded by multiple pools of neurons each with bell-shaped tuning centred over a different value. Indeed, that model predicts a larger aftereffect for less extreme adaptors, which will have a greater effect on neurons tuned to the average face. Only the opponent coding model predicts that a more physically extreme adaptor (e.g., a face with lips much smaller than the average) will produce a larger change in the perception of the average face than a less extreme adaptor because adaptation reduces neural response in proportion to the adapted firing rate (e.g., Maddess, McCourt, Blakeslee, \& Cunningham, 1988; Movshon \& Lennie, 1979).

By including adaptors both near and far from the average face in our task, we sought to determine whether potential differences in face coding between relatives of individuals with ASD and relatives of typical children are purely quantitative or also qualitative. If both groups show stronger aftereffects for far relative to near adaptors, this would suggest that the face space of relatives of children with ASD is qualitatively similar to that of relatives of typical children, in that it relies on norm-based rather than exemplar-based coding mechanisms.

\section{Methods}

\subsection{Participants}

Relatives of both children with autism (hereafter "ASD group") and typically developing children (hereafter, "TD group") were recruited for this study. The ASD group $(n=28)$ included 20 parents (13 mothers, 7 fathers) and 8 siblings ${ }^{1}$ (6 females) of individuals with ASD (14 families in total; see Table 1), who were recruited via an existing database of families with children with autism, whose children had received independent diagnoses according to DSM-IV criteria by a qualified child and adolescent psychiatrist or paediatrician. All families were identified for having at least one child diagnosed with an ASD. Primary characteristics of the ASD sample are reported in Table 1. As autism is much more prevalent in males than in females (M:F is 4:1, Fombonne, 2003), the familial risk for autism is likely to vary according to the gender of the unaffected siblings. The upper half of Table 2 shows gender and affected/unaffected status of all children in ASD families, with respect to the proband's diagnosis. As evident from the Table, the majority (11/14) of the families had either an unaffected child of female sex, or no

\footnotetext{
${ }^{1}$ All siblings came from different families.
}

Table 1

Characteristics of ASD relatives included in the final sample with respect to proband's diagnosis.

\begin{tabular}{lllr}
\hline & \multicolumn{2}{l}{ Proband's diagnosis } & \multirow{2}{*}{ Total } \\
\cline { 2 - 3 } & Autism & AS or HFA & \\
\hline Number of families & 9 & 5 & 14 \\
Multiplex & 1 & 2 & 3 \\
Simplex & 8 & 3 & 11 \\
Number of mothers & 8 & 5 & 13 \\
Number of fathers & 4 & 3 & 7 \\
Number of male siblings & 1 & 1 & 2 \\
Number of female siblings & 3 & 3 & 6 \\
\hline
\end{tabular}

${ }^{\text {a }}$ AS, Asperger Syndrome; HFA, high functioning autism.

Table 2

Family composition with respect to children's gender and affected status in ASD and TD groups.

\begin{tabular}{llc}
\hline Group & Children's gender & Number of families \\
\hline \multirow{2}{*}{ ASD } & M+/M- & 3 \\
& M+/F- & 4 \\
& M $/$ F $+/ F-$ & 1 \\
M $+/ M+/ F-$ & 1 \\
M + & 3 \\
& F+ & 2 \\
TD & M/F & $10^{\mathrm{a}}$ \\
& M/M & 1 \\
& F/F & 2
\end{tabular}

M, male; F, female; +, diagnosis of autism; -, no diagnosis of autism. All children in the families, including those that were excluded/not tested, are considered here.

a One family had 3 males, 1 female; one family had 2 females, 1 male.

unaffected children, suggesting that the familial risk for autism was relatively high in our sample. Many of the children with autism in our sample were not old enough ( $>7$ years) or of sufficient intellectual ability (IQ $>80$ ) to be assessed.

The TD group $(n=30)$ included 20 parents ( 11 mothers, 9 fathers) and 10 siblings ( 7 females) of typically developing children ( 13 families in total; 2 children came from the same family). TD families were recruited through advertising through local London schools. The lower half of Table 2 shows family composition of TD families in relation to children's gender. None of the parents or siblings in either group had ever received a diagnosis of ASD or was suspected to have ASD.

One additional inclusion criterion was that participants should perform above chance (i.e., 50\%) when identifying target faces of $80 \%$ identity strength (see Method). Three additional participants (one mother and one sibling of a child with autism and one father of a typically developing child) were tested but failed to meet this criterion and were therefore excluded from subsequent analyses.

When the groups were divided by relative status (parent, sibling), there were no significant differences between the ASD and TD groups in terms of chronological age (parents: $F(1,39)=1.70, p=0.20$; siblings: $F(1,17)=1.58, p=0.23$ ) or fullscale IQ scores (parents: $F(1,39)=2.16, p=0.15$; siblings: $F(1,17)=1.38, p=0.26$ ) as measured by administration of the Vocabulary and Matrices subtests of the Wechsler Abbreviated Scales of Intelligence (WASI; Wechsler, 1999) (see Table 3 for mean scores).

The study received ethical approval through the University College London Ethics Committee. All parents gave informed consent for themselves and their children prior to participation in this study.

\subsection{Face identity aftereffect task}

To measure the effects of adaptation on a previous identity-neutral average face, we administered a face identity aftereffect task using a child-friendly twoalternative forced-choice paradigm (see also Nishimura et al., 2008, and Pellicano et al., 2007).

\subsubsection{Stimuli}

Stimuli included grayscale photographs of two target male identities (Rob and Ted), which have been extensively validated in the previous aftereffect studies (see e.g., Jeffery et al., 2011; Nishimura et al., 2008; Pellicano et al., 2007; Pimperton, Pellicano, Jeffery, \& Rhodes, 2009). These original faces were used as training stimuli. A series of face images of graded identity strength (i.e., $40 \%, 60 \%$, 
$80 \%$ Rob; $40 \%, 60 \%, 80 \%$ Ted) were generated by morphing each original face towards the average face (constructed from a pool of 20 adult male faces) using Gryphon Morph 2.5 (Duane Maxwell, Gryphon Software Corporation 1992-1994). Test stimuli consisted of the average face (0\%) and $80 \%$ Ted, $80 \%$ Rob (see Fig. 2A). The effects of adaptation were expected to be most apparent for the average face. Baseline accuracy was expected to be high at $80 \%$ identity strengths, masking any aftereffect. The $80 \%$ test faces were included to check that participants could accurately identify "strong" versions of the faces. Test stimuli were $5.1 \mathrm{~cm}$ (height) $\times 4.8 \mathrm{~cm}$ (width) and subtended a visual angle of $5.84^{\circ} \times 5.50^{\circ}$ when viewed from a distance of approximately $50 \mathrm{~cm}$.

For each target face, two adapting stimuli (anti-faces) were constructed, lying on the same identity trajectory but extrapolated beyond the average to $40 \%$ (near adaptors) and 80\% (far adaptors) of original target strength (see Fig. 2B). Adapting stimuli were larger than test stimuli $(6.35 \mathrm{~cm} \times 6.35 \mathrm{~cm})$, subtending a visual angle of $7.27^{\circ} \times 7.27^{\circ}$. The size difference between adapting and test stimuli was included to ensure that any adaptation observed did not primarily reflect lowlevel (retinotopic) changes in the stimulus (Zhao \& Chubb, 2001).

\subsubsection{Procedure}

The aftereffect task included three different phases, two training phases and an adaptation phase, presented within the context of a game (Nishimura et al., 2008; Pellicano et al., 2007).

In the training phase, participants were introduced to Ted and Rob target identities (100\% identity strength) as "police team captains". They were told to look at the faces for as long as they wished until they thought they could tell them apart. On each trial, participants saw a black fixation cross $(150 \mathrm{~ms})$ and an interstimulus interval $(500 \mathrm{~ms}$ ) followed by an image of either Ted or Rob, and participants were simply asked to identify them by appropriate key press (' $x$ ' for Ted and ' ' for Rob). In the first block, participants were asked to identify six images (three each of Rob/Ted), which were presented until participants made a response. One sibling of a typically developing child and one sibling of a child with autism needed an additional six trials to identify all six target faces correctly. In the second block, participants viewed 12 additional faces of $100 \%$ Rob and $100 \%$
Ted (six of each) in a randomized order, which remained on screen for $400 \mathrm{~ms}$ only. Two siblings of typically developing children did not reach criterion ( $\geq 10$ trials correct) and therefore completed an additional six trials.

Next, participants were introduced to Rob and Ted's "team-mates" ( $40 \%$ and $60 \%$ identity strengths of Rob and Ted) in order to ensure that participants knew how to respond to weak versions of the targets that resemble the weak impression of identity the average face takes on after adaptation. Participants saw 12 faces presented twice at each of the three identity strengths $40 \%, 60 \%$ and $100 \%$ Rob: "Team Rob"; 40\%, 60\% and 100\%: "Team Ted") in a randomized order. Each face remained on screen until participant identified to which "team" the target face belonged. Upon reaching criterion ( $\geq 8$ trials correct), participants then completed a final block of 12 trials ( 6 faces from Team Rob and 6 from Team Ted) during which target faces were presented for $400 \mathrm{~ms}$ only. One sibling of a typically developing child repeated the initial set of 12 trials because they failed to reach criterion. Auditory feedback regarding participant's performance was provided throughout the training phase.

During the adaptation phase, participants were presented with a cover story in which robbers (antifaces) were carrying out a burglary. They were instructed to identify which police-team (Team Rob or Team Ted) had caught the robber. Trials consisted of a black fixation cross $(150 \mathrm{~ms})$, a blank screen $(500 \mathrm{~ms})$, the adapting face or 'robber' $(5000 \mathrm{~ms})$ followed by the target face $(400 \mathrm{~ms})$. Participants were reminded to watch the adapting face (robber) carefully for the entire time he was shown so that they would not miss the onset of the target face (policeman) who would appear very briefly. A total of 120 trials were presented to participants, including 80 trials with the average face (0\%) as the target face and 20 trials each with $80 \%$ Rob and $80 \%$ Ted as target faces, which were divided into five blocks of 24 trials and presented in a randomized order. There were more trials for the average face $(0 \%)$ since we were primarily interested in the extent to which adaptation to a particular identity (antiRob, antiTed) biased perception towards this identity, thus making the average face look more like the original face (Rob, Ted). The adapting faces were either near (40\% antiRob: 30 trials; $40 \%$ antiTed: 30 trials) or far (80\% antiRob: 30 trials; $80 \%$ antiTed: 30 trials) from the average.

The adaptation phase took approximately $20 \mathrm{~min}$ to complete. No feedback was provided during this phase. Each of the five blocks began by asking

Table 3

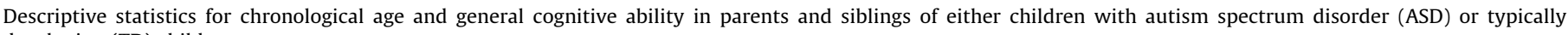
developing (TD) children.

\begin{tabular}{|c|c|c|c|c|}
\hline & \multicolumn{2}{|l|}{ Parents } & \multicolumn{2}{|l|}{ Siblings } \\
\hline & $\begin{array}{l}\text { ASD }(n=20) \\
M(S D) \\
\text { Range }\end{array}$ & $\begin{array}{l}\text { TD }(n=20) \\
M(\mathrm{SD}) \\
\text { Range }\end{array}$ & $\begin{array}{l}\text { ASD }(n=8) \\
M(\mathrm{SD}) \\
\text { Range }\end{array}$ & $\begin{array}{l}\text { TD }(n=10) \\
M(\mathrm{SD}) \\
\text { Range }\end{array}$ \\
\hline Age (years; months) & $\begin{array}{l}45 ; 3(4 ; 4) \\
34 ; 4-52 ; 0\end{array}$ & $\begin{array}{l}43 ; 5(4 ; 5) \\
34 ; 11-53 ; 6\end{array}$ & $\begin{array}{l}12 ; 5(2 ; 11) \\
7 ; 11-16 ; 3\end{array}$ & $\begin{array}{l}10 ; 9(2 ; 8) \\
7 ; 9-15 ; 2\end{array}$ \\
\hline Full-scale IQ & $\begin{array}{l}115.40(11.01) \\
103-138\end{array}$ & $\begin{array}{l}119.90(8.12) \\
105-134\end{array}$ & $\begin{array}{l}102.50(12.75) \\
86-119\end{array}$ & $\begin{array}{l}110.20(14.56) \\
86-130\end{array}$ \\
\hline
\end{tabular}

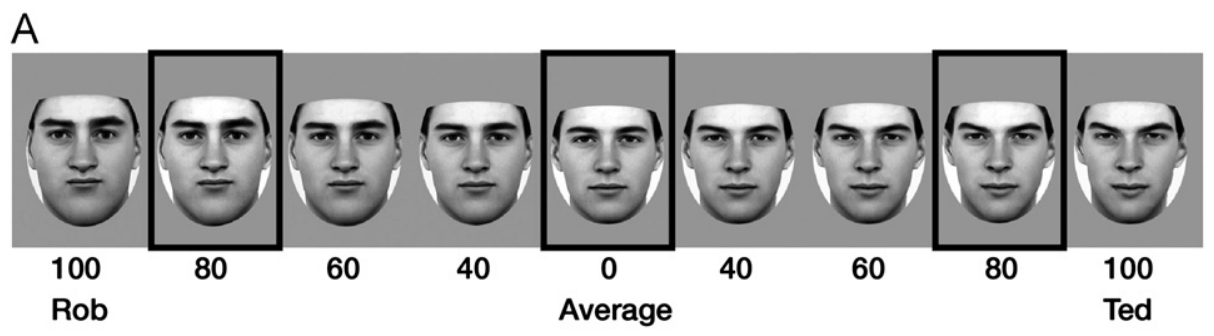

B
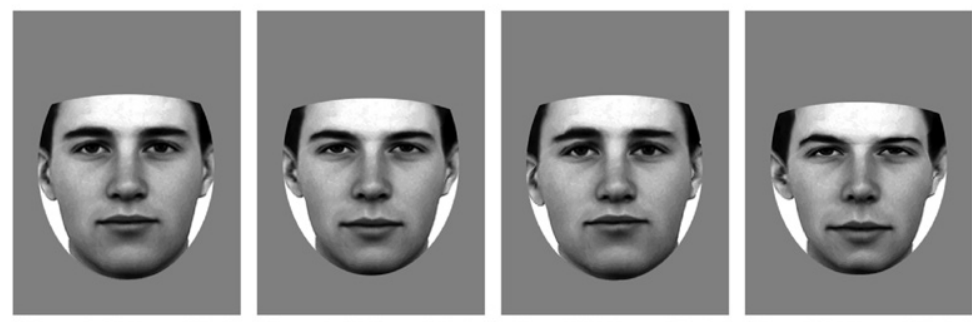

Near (40\%) antiTed Near (40\%) antiRob

Far $(80 \%)$ antiTed

Far $(80 \%)$ antiRob

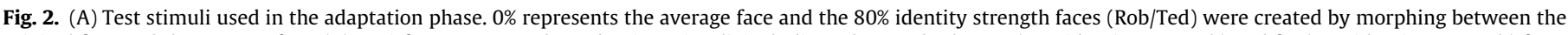

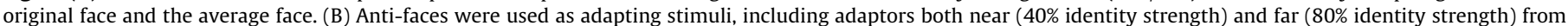
the average face. 
participants to identify the original two faces. The experimenter monitored the participant's attention throughout the experiment to ensure that they fixated on the adapting face for the full $5 \mathrm{~s}$.

\subsection{General procedure}

Participants were tested individually in a quiet room either at home or at the university. The WASI was always administered prior to the face identity aftereffect task, which was presented on an Apple Macbook (13-inch matte LCD screen) OS X (Version 10.4.9) using Cedrus SuperLab 4.0.7b software. The entire session lasted approximately $1 \mathrm{~h}$.

\section{Results}

An initial ANOVA on the proportion of correct responses for the $80 \%$ target faces with group (relatives of children with ASD, relatives of TD children) and relative status (parent, sibling) showed no main effects of group, relative status or any interactions involving these factors (all $F s<2.95$, all $p s>0.16$ ), indicating that relatives of children with $\operatorname{ASD}(M=0.93, \mathrm{SD}=0.08)$ could recognise strong versions of the target faces just as well as relatives of TD children $(M=0.96, \mathrm{SD}=0.04)^{2}{ }^{2}$

The aftereffect - the dependent variable of interest - was calculated by subtracting the proportion of "Ted" responses after adapting to antiRob from the proportion of "Ted" responses after adapting to antiTed for each adapting condition (far, near) separately. An aftereffect in the predicted direction should yield a positive difference, since adapting to antiTed should make the average face look more like Ted while adapting to antiRob should make the average look more like Rob.

The scatterplots in Fig. 3 show the size of the aftereffect for each individual participant in each group and condition (far, near) separately. The aftereffects of relatives of children with autism appear smaller than those of relatives of typically developing children, particularly in the far condition. This was confirmed by repeated-measures ANOVA on participants' aftereffect scores with adaptor strength (far, near) as the within-participant factor and group (relatives of children with ASD, relatives of TD children) and relative status (parent, sibling) as the betweenparticipant factors. Note that a preliminary ANOVA including gender as an additional factor showed no main effect of gender, $F(1,50)=0.01, p=0.94$, or interaction between gender and any of the other variables (all $F s<2.75$, all $p s>0.10$ ), so this variable was not considered further.

There was a significant main effect of adaptor strength, $F(1,54)=48.69, p<0.001, \eta p^{2}=0.47$, with larger aftereffects for the far adaptors $(M=0.33, \mathrm{SD}=0.23)$ than the near adaptors $(M=0.11, \mathrm{SD}=0.18)$. There was also a main effect of group, $F(1,54)=4.07, p=0.04, \eta p^{2}=0.07$, with relatives of TD children experiencing slightly larger aftereffects $(M=0.26, \mathrm{SD}=0.19)$ than the relatives of children with ASD $(M=0.18, S D=0.14)$, as well as a significant main effect of relative status, $F(1,54)=9.23, p<0.01$. Siblings showed larger aftereffects than parents across both conditions (parents: $M=0.17, \mathrm{SD}=0.13$; siblings: $M=0.32$, $\mathrm{SD}=0.22$ ). Relative status, however, did not interact with adaptor strength or with group (both $F s<0.69$, both $p s>0.41$ ). ${ }^{3}$

Importantly, there was a significant interaction between group and adaptor strength, $F(1,54)=11.41, \quad p=0.001, \quad \eta p^{2}=0.17$.

\footnotetext{
${ }^{2}$ Although the assumption of normality was not satisfied for these data, a non-parametric permutation ANOVA produced identical results, with all permutation $p$-values exceeding 0.05 .

${ }^{3}$ As noted in the Method section, the TD group included two sibling pairs. To ensure that their relatedness did not bias our results, we reran the analysis first by excluding both siblings in each pair and then by excluding one sibling per pair (in all four possible combinations). The pattern of results did not differ to the one reported above. These two sibling pairs were therefore retained in the final analysis.
}

Within-group paired-sample $t$ tests demonstrated that both groups showed significantly stronger aftereffects when the adapting face was further from, compared to when it was closer to, the average face (relatives of children with ASD, $t(27)=4.10$, $p<0.001$; relatives of TD children: $t(29)=6.43, p<0.001$ ). Yet the magnitude of the difference between near and far aftereffects was significantly greater for relatives of typically developing children $(M=0.31 ; \mathrm{SD}=0.26)$ than for relatives of children with ASD $(M=0.12 ; \mathrm{SD}=0.15), t(56)=3.38, p=0.001$.

Furthermore, independent samples $t$ tests showed that relatives of children with ASD showed significantly smaller aftereffects $(M=0.24, S D=0.18)$ compared with relatives of TD children $(M=0.41, \mathrm{SD}=0.25)$ in the far condition, $t(56)=3.08$, $p=0.003$, but not in the near condition (ASD relatives: $M=0.12$; $\mathrm{SD}=0.13$; TD relatives: $M=0.10 ; \mathrm{SD}=0.22), t(56)=0.30, p=0.76$ (see Fig. 3). One-sample $t$ tests showed that, for participants in both relative groups, aftereffects in far (both $t \mathrm{~s}>6.91$, $p_{\text {Bonf }}<0.001$ ) and near (both $t \mathrm{~s}>2.59, p_{\text {Bonf }}<0.05$ ) adapting conditions were nevertheless significantly greater than 0 .

\section{Discussion}

This study investigated whether parents and siblings of children with autism show diminished aftereffects to facial identity as children with autism do (Pellicano et al., 2007). Using a face identity adaptation task, we demonstrated that, for relatives of typically developing children, adaptation to antiRob caused the average face to appear more Rob-like, and the magnitude of this bias in perception (the aftereffect) was stronger when the adapting face was further from the average face than when it was closer. Relatives of children with ASD showed a similar pattern of results but their aftereffects were significantly attenuated compared with those of relatives of TD children when the adapting stimuli were located further away from the average face. These findings are consistent with those of Pellicano et al. (2007), who found reduced aftereffects in children with ASD using a task with far adaptors only, and extend them to first-degree relatives of children with ASD.

The fact that both groups showed comparable recognition accuracy on high strength (i.e., 80\%) target faces suggests that the results cannot be attributed to differences in the ability of participants to identify strong versions of the targets in our task and also speaks against the possibility that relatives were simply not paying attention during the adaptation task. This study therefore provides the first evidence of atypicalities in adaptive face coding mechanisms in relatives of children with ASD, which could be a candidate endophenotype for autism.

Consistent with the previous research showing that more extreme adaptors produce larger aftereffects in perception of the average face (Jeffery et al., 2010; Robbins et al., 2007), relatives exhibited larger aftereffects when the adaptor was further from the average than when it was closer to it. This pattern of results fits with the idea that faces are coded relative to a norm or prototypical face. The fact that relatives of children with ASD showed stronger aftereffects for far, compared with near, adaptors suggest that they are using qualitatively similar (opponent-coding) mechanisms to code facial identity as relatives of TD children. The magnitude of the near-far effect was nevertheless significantly attenuated in relatives of children with ASD, which might be due to differences in the degree of tuning of opponent-coded neural populations. Such populations might be less sharply tuned in relatives of children with ASD, which could result in less efficient norm-based face-coding mechanisms.

The next step will be to clarify whether children with ASD also show the same pattern as their relatives - one in which their 


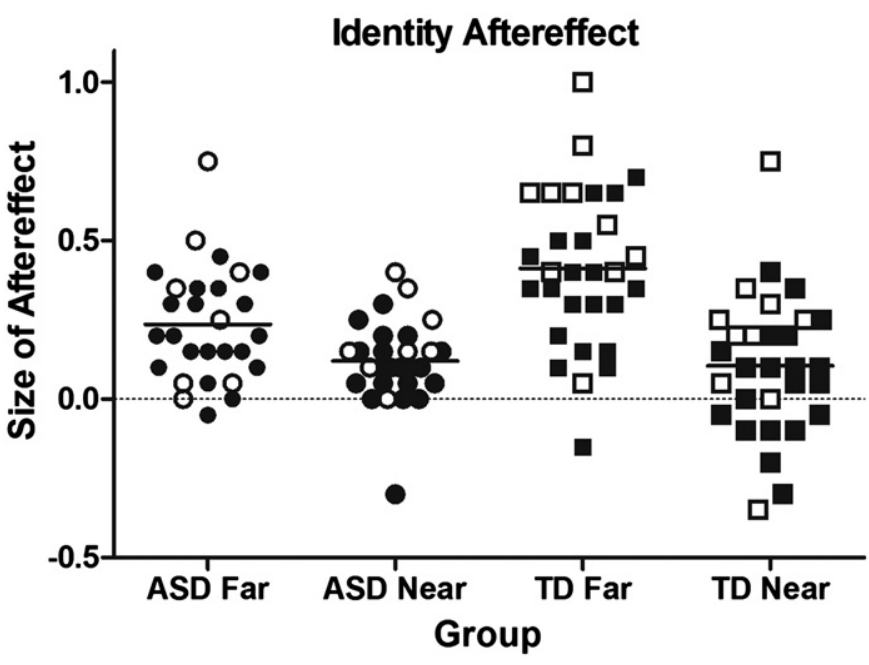

Fig. 3. Scatterplots showing the size of the aftereffect for each individual participant in each group (ASD, TD) and condition (Far, Near) separately. Circles: relatives of ASD children; squares: relatives of TD children, filled shapes: parents; open shapes: children. The size of the aftereffect is calculated as the proportion of "Ted" responses after adapting to antiTed minus the proportion of "Ted" responses after adapting to antiRob. An aftereffect in the predicted direction should yield a positive difference, since adapting to antiTed should make the average face look more like Ted while adapting to antiRob should make the average look more like Rob. Horizontal lines indicate the mean value for each group.

face-space follows a norm-based (opponent-coding) organisation but is characterised by reduced sensitivity to far but not near adaptors. Pellicano et al. (2007) provided initial evidence that identity aftereffects are attenuated in children with ASD. Future work should seek to establish whether the same pattern of atypicalities exist both in children with ASD and in their unaffected relatives, with the size of the aftereffect decreasing monotonically with increasing expression of autistic symptoms.

Although the experimenter closely monitored participants' gaze patterns to ensure that relatives from both groups were carefully inspecting the faces, it remains possible that relatives of children with ASD were attending to different parts of the faces compared with relatives of typically developing children. Adolphs et al. (2008) showed that some parents of children with autism required more information from the mouth and less information from the eyes than parents of typically developing children to judge emotions. Perhaps, then, our relatives of children with ASD were not attending to the "right" part of the face. The fact that the groups of relatives achieved similarly high rates of recognition accuracy with high-strength identities (80\% Rob/Ted) suggests this might not be the case, although the use of eye-tracking methodology would be needed to rule out this explanation entirely.

These findings raise several outstanding questions regarding the extent and nature of diminished face adaptation in individuals with autism and their relatives. First, it will be important to clarify whether diminished adaptation in relatives of children with autism is specific to faces or whether it might extend to the coding of other complex visual stimuli, perhaps reflecting a more pervasive visual processing difference in individuals with autism (see also Lombardo, Chakrabarti, \& Baron-Cohen, 2009). Recent work using figural distortion aftereffects with children with autism suggests that diminished adaptation might be selective for faces (Ewing, Pellicano, \& Rhodes, 2011b).

Second, in our sample, the families of children with ASD varied with respect to the actual family composition, with the majority of the families having either an unaffected child of female sex or no unaffected children, suggesting a relatively a high familial risk for autism. It is therefore possible that face-coding atypicalities, like other behavioural traits (see e.g., Schwichtenberg, Young, Sigman et al., 2010; Virkud, Todd, Abbacchi et al., 2009) are more prevalent in families with high genetic load for autism. It will be important for future studies to examine the relationship between degree of genetic liability and face-coding atypicalities more directly, by using larger samples, by controlling for family composition and by including dimensional ratings of autisticlike traits (cf. Adolphs et al., 2008, see Pellicano, 2008). Doing so should provide greater clarity regarding the neurocognitive pathways involved in the genetic liability for autism.

Finally, investigation of the neural mechanisms underlying reduced face adaptation aftereffects in autistic children and their relatives would be beneficial. Kleinhans et al. (2009) showed that repeated exposure to faces resulted in significantly reduced activation of the amygdala in typical adults but this neural adaptation was attenuated in adults with autism. Additional research is needed to clarify whether differences in face adaptation are also observed in relatives of children with autism in both the amygdala and other key "face areas" (e.g., the fusiform gyrus) and how they relate to behavioural performance in face processing tasks.

Previous research on the broad autism phenotype has mostly focused on observable behavioural differences between relatives of individuals with and without ASD (Bolton et al., 1994; Losh et al., 2008; Murphy et al., 2000; Piven et al., 1997) rather than identifying atypicalities in neurocognitive mechanisms underlying such differences. No study so far, however, has provided unambiguous evidence of the source of these atypicalities, by explaining how and why faces are processed atypically in ASD. The discovery of specific endophenotypes, which are held to be more proximal to relevant gene action than behavioural outcomes (Gottesman \& Gould, 2003), should edge us closer to isolating candidate genes that confer susceptibility to autism. Diminished adaptive face coding might be one such endophenotype.

\section{Acknowledgements}

We are extremely grateful to all of the families that generously took part in this research. C.F. was supported by a Swiss National Science Foundation (FNS) Fellowship for Young Researchers during the period of this research. Research at the Centre for Research in Autism and Education (CRAE) is supported by The Clothworkers' Foundation and Pears Foundation (L.G. \& E.P.). G.R., L.J. and E.P. were supported by the Australian Research Council Centre of Excellence in Cognition and its Disorders (project number CE110001021), an Australian Research Council Professorial Fellowship (G.R) and by Australian Research Council Discovery Project (DP0770923, L.J., G.R., E.P.). Many thanks to Mayu Nishimura and Daphne Maurer for co-creating the "Robbers Task", Libby Taylor for help setting up the task and Marc Stears for comments on a previous version of this manuscript.

\section{References}

Adolphs, R., Spezio, M. L., Parlier, M., \& Piven, J. (2008). Distinct face-processing strategies in parents of autistic children. Current Biology, 18, 1090-1093, http://dx. doi.org/10.1016/j.cub.2008.06.073.

American Psychiatric Association. (2000). Diagnostic and statistical manual of mental disorders (4th ed., Text Revision) (DSM-IV-TR). Washington, DC: American Psychiatric Association.

Bailey, A., Le Couteur, A., Gottesman, I., Bolton, P., Simonoff, E., Yuzda, E., et al. (1995). Autism as a strongly genetic disorder: Evidence from a British twin study. Psychological Medicine, 25, 63-77, http://dx.doi.org/10.1017/S0033291700028099.

Bailey, A., Palferman, S., Heavey, L., \& Le Couteur, A. (1998). Autism: The phenotype in relatives. Journal of Autism and Developmental Disorders, 28, 369-392, http://dx.doi.org/10.1023/A:1026048320785. 
Bishop, D. V. M., Maybery, M., Wong, D., Maley, A., \& Hallmayer, J. (2006). Characteristics of the broader phenotype in autism: A study of siblings using the children's communication checklist-2. American Journal of Medical Genetics Part B: Neuropsychiatric Genetics(141B), 117-122, http://dx.doi.org/10.1002/ ajmg.b.30267.

Bolton, P., Macdonald, H., Pickles, A., Rios, P., Goode, S., Crowson, M., et al. (1994). A case-control family history study of autism. Journal of Child Psychology and Psychiatry, 35, 877-900, http://dx.doi.org/10.1111/j.1469-7610.1994.tb02300.x.

Boucher, J., Lewis, V., \& Collis, G. (1998). Familiar face and voice matching and recognition in children with autism. Journal of Child Psychology and Psychiatry, 39, 171-182, http://dx.doi.org/10.1111/1469-7610.00311.

Dalton, K. M., Nacewicz, B. M., Alexander, A. L., \& Davidson, R. J. (2005). Gaze-fixation, brain activation, and amygdala volume in unaffected siblings of individuals with autism. Biological Psychiatry, 61, 512-520, http://dx.doi.or g/10.1016/j.biopsych.2006.05.019.

Dawson, G., Webb, S. J., \& McPartland, J. (2005). Understanding the nature of face processing impairment in autism: Insights from behavioral and electrophysiological studies. Developmental Neuropsychology, 27, 403-424, http://dx.doi.o rg/10.1207/s15326942dn2703_6.

Dawson, G., Webb, S., Schellenberg, G., Aylward., E., Richards, T., Dager, S., et al. (2002). Defining the phenotype of autism: Genetic, brain, and behavioral perspectives. Development and Psychopathology, 14, 581-611, http://dx.doi.org/ $10.1017 /$ S0954579402003103.

Ewing, E., Pellicano, E., \& Rhodes, G. (2011a). Assessing the selectivity of faceprocessing impairments in children with an autism spectrum disorder. (Manuscript submitted for publication).

Ewing, E., Pellicano, E., \& Rhodes, G. (2011b). Atypical updating of face representations with experience in children with autism.

Falck-Ytter, T., \& von Hofsten, C. (2011). How special is social looking in ASD: A review. Progress in Brain Research, 189, 209-222, http://dx.doi.org/10.1016/ B978-0-444-53884-0.00026-9.

Flint, J., \& Munafò, M. R. (2007). The endophenotype concept in psychiatric genetics. Psychological Medicine, 37, 163-180, http://dx.doi.org/10.1017/ S0033291706008750.

Folstein, S., \& Rutter, M. (1977). Infantile autism: A genetic study of 21 twin-pairs. Journal of Child Psychology and Psychiatry, 18, 291-293, http://dx.doi.org/ 10.1111/j.1469-7610.1977.tb00443.x.

Fombonne, E. (2003). Epidemiological surveys of autism and other pervasive developmental disorders: An update. Journal of Autism and Developmental Disorders, 33, 365-382, http://dx.doi.org/10.1023/A:1025054610557.

Geschwind, D. H. (2011). Genetics of autism spectrum disorders. Trends in Cognitive Sciences, 15, 409-416, http://dx.doi.org/10.1016/j.tics.2011.07.003.

Gottesman, I. I., \& Gould, T. D. (2003). The endophenotype concept in psychiatry: Etymology and strategic intentions. American Journal of Psychiatry, 160, 636-645, http://dx.doi.org/10.1176/appi.ajp.160.4.636.

Jeffery, L., McKone, E., Haynes, R., Firth, E., Pellicano, E., \& Rhodes, G. (2010). Fourto-six-year-old children use norm based coding in face-space. Journal of Vision, 10, 1-19, http://dx.doi.org/10.1167/10.5.18.

Jeffery, L., Rhodes, G., McKone, E., Pellicano, E., Crookes, K., \& Taylor, E. (2011) Distinguishing norm-based from exemplar-based coding of identity in children: Evidence from face identity aftereffects. Journal of Experimental Psychology: Human Perception and Performance, 37(6), 1824-1840, http://dx.doi.org/10.1037/ a0025643.

Joseph, R. M., \& Tanaka, J. (2002). Holistic and part-based face recognition in children with autism. Journal of Child Psychology and Psychiatry, 43, 1-14, http: //dx.doi.org/10.1111/1469-7610.00142.

Kleinhans, N. M., Johnson, L. C., Richards, T., Mahurin, R., Greenson, J., Dawson, G., et al. (2009). Reduced neural habituation in the amygdala and social impairments in autism spectrum disorders. American Journal of Psychiatry, 166 467-475, http://dx.doi.org/10.1176/appi.ajp.2008.07101681.

Klin, A., Jones, W., Schultz, R., Volkmar, F., \& Cohen, D. (2002). Visual fixation patterns during viewing of naturalistic social situations as predictors of social competence in individuals with autism. Archives of General Psychiatry, 59, 809-816.

Leopold, D. A., O'Toole, A. J., Vetter, T., \& Blanz, V. (2001). Prototype-referenced shape encoding revealed by high-level aftereffects. Nature Neuroscience, 4 , 89-94, http://dx.doi.org/10.1038/82947.

Lombardo, M. V., Chakrabarti, B., \& Baron-Cohen, S. (2009). The amygdala in autism: Not adapting to faces?. American Journal of Psychiatry, 166, 395-397, http://dx.doi. org/10.1176/appi.ajp.2009.09010044.

Losh, M., Childress, D., Lam, K., \& Piven, J. (2008). Defining key features of the broad autism phenotype: A comparison across parents of multiple- and singleincidence autism families. American Journal of Medical Genetics Part B: Neuropsychiatric Genetics, 147B, 424-433, http://dx.doi.org/10.1002/ajmg.b.30612.
Losh, M., \& Piven, J. (2007). Social-cognition and the broad autism phenotype: Identifying genetically meaningful phenotypes. Journal of Child Psychology and Psychiatry, 48, 105-112.

Maddess, T., McCourt, M., Blakeslee, B., \& Cunningham, R. (1988). Factors governing the adaptation of cells in area-17 of the cat visual cortex. Biological Cybernetics, 59, 229-236.

Movshon, J. A., \& Lennie, P. (1979). Pattern-selective adaptation in visual cortical neurones. Nature, 278, 850-852, http://dx.doi.org/10.1038/278850a0.

Murphy, M., Bolton, P. F., Pickles, A., Fombonne, E., Piven, J., \& Rutter, M. (2000) Personality traits of the relatives of autistic probands. Psychological Medicine, 30, 1411-1424.

Neumann, D., Spezio, M. L., Piven, J., \& Adolphs, R. (2006). Looking you in the mouth: Abnormal gaze in autism resulting from impaired top-down modulation of visual attention. Social Cognitive and Affective Neuroscience, 1, 194-202, http://dx.doi.org/10.1093/scan/nsl030.

Nishimura, M., Maurer, D., Jeffery, L., Pellicano, E., \& Rhodes, G. (2008). Fitting the child's mind to the world: Adaptive norm-based coding of facial identity in 8-year-olds. Developmental Science, 11, 620-627, http://dx.doi.org/10.1111/ j.1467-7687.2008.00706.x.

Pellicano, E., Jeffery, L., Burr, D., \& Rhodes, G. (2007). Abnormal adaptive facecoding mechanisms in children with autism spectrum disorder. Current Biology, 17, 1508-1512, http://dx.doi.org/10.1016/j.cub.2007.07.065.

Pellicano, E. (2008). Autism: Face-processing clues to inheritance. Current Biology 18, R748-R750, http://dx.doi.org/10.1016/j.cub.2008.07.004.

Pimperton, H., Pellicano, E., Jeffery, L., \& Rhodes, G. (2009). The role of higher level adaptive coding mechanisms in the development of face recognition. Journal of Experimental Child Psychology, 104, 229-238, http://dx.doi.org/10.1016/ j.jecp.2009.05.009.

Piven, J., Palmer, P., Jacobi, D., Childress, D., \& Arndt, S. (1997). Broader autism phenotype: Evidence from a family history study of multiple-incidence autism families. American Journal of Psychiatry, 154, 185-190.

Rhodes, G., \& Jeffery, L. (2006). Adaptive norm-based coding of facial identity. Vision Research, 46, 2977-2987, http://dx.doi.org/10.1016/j.visres.2006.03.002.

Rhodes, G., \& Leopold, D. A. (2011). Adaptive norm-based coding of face identity. In: A. W. Calder, G. Rhodes, M. H. Johnston, \& J. V. Haxby (Eds.), Oxford Handbook of Face Perception. Oxford: Oxford University Press.

Rhodes, G., Robbins, R., Jaquet, E., McKone, E., Jeffery, L., \& Clifford, C. W. (2005) Adaptation and face perception. In: C. W. Clifford, \& G. Rhodes (Eds.) Fitting the mind to the world: Adaptation and after effects in high-level vision (pp. 213-240). Oxford: Oxford University Press.

Robbins, R. McKone, E \& Edwards, M. (2007). Aftereffects for face attributes with different natural variability: Adapter position effects and neural models. Journal of Experimental Psychology: Human Perception and Performance, 33, 570-592.

Rump, K. M., Giovannelli, J. L., Minshew, N. J., \& Strauss, M. S. (2009). The development of emotion recognition in individuals with autism. Child Devel opment, 80, 1434-1447, http://dx.doi.org/10.1111/j.1467-8624.2009.01343.x.

Schwichtenberg, A. J., Young, G. S., Sigman, M., Hutman, T., \& Ozonoff, S. (2010) Can family affectedness inform infant sibling outcomes of autism spectrum disorders?. Journal of Child Psychology and Psychiatry, 51, 1021-1030.

Spezio, M. L., Adolphs, R., Hurley, R. S. E., \& Piven, J. (2007). Abnormal use of facia information in high-functioning autism. Journal of Autism and Developmental Disorders, 37, 929-939, http://dx.doi.org/10.1007/s10803-006-0232-9.

Virkud, Y. V., Todd, R. D., Abbacchi, A. M., Zhang, Y., \& Costantino, J. N. (2009) Familial aggregation of quantitative autistic traits in multiplex versus simplex autism. American Journal of Medical Genetics, Part B-Neuropsychiatric Genetics, $150 B, 328-334$

Wallace, S., Coleman, M., \& Bailey, A. (2008a). Face and object processing in autism spectrum disorders. Autism Research, 1, 43-51, http://dx.doi.org/10.1002/aur.7.

Wallace, S., Coleman, M., \& Bailey, A. (2008b). An investigation of basic facial expression recognition in autism spectrum disorders. Cognition and Emotion, 22, 1353-1380, http://dx.doi.org/10.1080/02699930701782153.

Wallace, S., Coleman, M., Pascalis, O., \& Bailey, A. (2006). A study of impaired judgment of eye gaze direction and related face processing deficits in autism spectrum disorders. Perception, 35, 1651-1664, http://dx.doi.org/10.1068/ p5442.

Wallace, S., Sebastian, C., Pellicano, E., Parr, J., \& Bailey, A. (2010). Brief Report: Face processing abilities in relatives of individuals with Autism. Autism Research, 3, 345-349, http://dx.doi.org/10.1002/aur.161.

Wechsler, D. (1999). Wechsler Abbreviated Scale of Intelligence. New York: Psychological Corporation.

Wilson, E. C., Freeman, P., Brock, J., Burton, M. A., \& Palermo, R. (2010). Facial identity recognition in the broader autism phenotype. PloS One, 5, 1-7, http://dx doi.org/10.1371/journal.pone.0012876.

Zhao, L., \& Chubb, C. (2001). The size-tuning of the face-distortion after-effect. Vision Research, 41, 2979-2994, http://dx.doi.org/10.1016/S0042-6989(01)00202-4. 